\title{
Exploring the Perceived Integrations Between Assessment and Metacognition: A Qualitative Inquiry of Three Award-Winning Teacher Educators' Conceptions of Assessment in a Hong Kong University Context
}

\author{
Jing Wang * \\ Guangdong University of Foreign Studies, Guangzhou, China
}

OPEN ACCESS

Edited by:

Gavin T. L. Brown,

The University of Auckland,

New Zealand

Reviewed by:

Christopher DeLuca,

Queen's University, Canada

Ana Remesal,

University of Barcelona, Spain

${ }^{*}$ Correspondence:

Jing Wang

wjcc99@gmail.com

Specialty section:

This article was submitted to Assessment, Testing and Applied

Measurement,

a section of the journa

Frontiers in Education

Received: 26 July 2019 Accepted: 18 December 2019 Published: 28 January 2020

Citation:

Wang J (2020) Exploring the Perceived Integrations Between Assessment and Metacognition: A

Qualitative Inquiry of Three Award-Winning Teacher Educators' Conceptions of Assessment in a

Hong Kong University Context.

Front. Educ. 4:157.

doi: 10.3389/feduc.2019.00157
This paper sets out to depict the interactions and integrations between teacher conceptions of assessment and their knowledge of and pedagogical understanding of metacognition. It aims to reframe teacher conceptions of assessment and direct the conceptions to improvement of learning and teaching from a metacognitive perspective, by closely observing the lessons and interviewing three award-winning teacher educators from a Hong Kong university context. The rich qualitative data, deriving from a multiple-case longitudinal design show that the integration was manifested, in different ways, between the conceptions of assessment and knowledge of and pedagogical understanding of metacognition across the three case teachers. Two pertinent issues were discussed concerning perceived dual roles in students in response to both accountability and learning purpose of assessment, and priority of classroom assessment in relation to metacognitive engagement. However exploratory, the perspectives regarding various real classroom decisions and dilemmas, and pedagogical insights that emerged from the specific setting may carry resonance for teachers, researchers and teacher-educators.

Keywords: conceptions of assessment, assessment literacy, metacognition, teacher educator, higher education, Hong Kong

\section{INTRODUCTION}

Conception of assessment is recognized as an integral mediating factor of assessment literacy (Xu and Brown, 2016). It is evidenced that conceptions of teaching, learning, assessment, curriculum, and teacher efficacy are interconnected (Brown, 2006) and strongly impact on pedagogical practices and performance (Pajares, 1992). It is, thus, critical to make such conceptions and the relationships of those conceptions among and between each other explicit and visible, especially when conception change is expected in professional development activities (Borko et al., 1997). Teachers' conceptions of assessment are affected by the level of assessment literacy training 
oriented by a multi-dimension view of assessment. Brown (2008) proposes that the assessment literacy training could move toward an assessment for learning paradigm because teachers' purely administrative or negative views of assessment may not necessarily achieve the objectives of the training unless they are directed to greater commitment to improvement purpose. Whereas, Looney (2011) encourages training programmes bring both classroom-based assessment (formative and summative) as well as large-scale, standards-based assessments, thus directing teachers toward a balanced perception toward different purpose of assessment. Hence teacher conceptions of assessment are arguably placed at the heart of the success of assessment literacy training and assessment change.

Research suggests that the major premise of the improvement conception is that assessment improves learning and teaching (Black and Wiliam, 1998), yet conceptions are divergent and complex (Van den Berg, 2002), and sometimes logically inconsistent (Cheung and Wong, 2002; Rex and Nelson, 2004). The questions regarding how to better understand dimensions of teacher conceptions of assessment so as to better guide teachers' assessment decision-making, therefore, have remained a critical issue in the research on assessment literacy.

Teacher conceptions of assessment have both cognitive and affective dimensions, which are framed by their epistemological beliefs of teaching and learning (Xu and Brown, 2016). In reaching out to our cognitive system, metacognition has long been recognized as the "control center" and a catalyst for learning (Ibabe and Jauregizar, 2010). Much evidence has shown that those who engage in meaningful and deep-learning, are those who can activate their metacognitive skillfulness (De Backer et al., 2012); and that teaching students to be metacognitive in learning is crucial (Sternberg, 1998; Ottenhoff, 2011). Metacognition, seemly to be separated from assessment literature, yet as a disposition of thinking and learning (Flavell, 1979), is in fact closely related to how we are taught and what and how we learn in the assessment process (Aguirre and Speer, 1999; Zohar, 1999). Empirical studies have demonstrated significant gains in metacognitive functions when teacher integrate assessment with their instruction (Black and Wiliam, 1998; Earl, 2003; Willis, 2010). Understanding teachers' theoretical knowledge about metacognition (Zohar and Barzilai, 2013) as well as pedagogical knowledge regarding effective instruction for teaching students to be metacognitive (Wilson and Bai, 2010), has a strong impact on teaching and learning. Thus, research on how conceptions of metacognition interact with and direct conceptions of assessment to students' own learning and the quality of teaching, is intriguing as it offers a new angle of examining teacher conceptions of assessment and provides insights into the considerations that teachers employ when making assessment training decisions. Hence, exploring teachers' conceptions of assessment from a metacognitive perspective offers an alternative dimension to interpret and understand what it entails.

Although some studies have acknowledged the role that teacher conceptions play in shaping assessment literacy (Brown, 2008; Levy-Vered and Alhija, 2015), it has hitherto attracted only modest attention in the literature to legitimate this dimension. While existing literature related to teacher conceptions of assessment mainly focuses on pre-service and in-service teachers (e.g., DeLuca and Bellara, 2013; Scarino, 2013; Cowie et al., 2014), less attention has paid to teacher educators' knowledge and understanding of assessment.

Understanding teacher educators' conceptions of assessment in a university context is particularly important due to three reasons. First, teacher educators' assessment literacy is highly consequential as their students are pre-service teachers who are going to impact numerous EFL classrooms in the future. Preservices teachers' conceptions of assessment are sharpened and reconstructed through "apprenticeship of observation" (Lortie, 1975; cited in Xu and Brown, 2016) may largely depend on the quality of assessment experiences modeled by the university professors or associate teachers in schools (Graham, 2005), and by reflection and collaboration about university classroom experiences (Wise et al., 1991; Howley et al., 2013). Second, there seems to exist a discrepancy between what experts (e.g., professors in colleges of education) and teachers consider to be important knowledge (Xu and Brown, 2016), and to bridge it requires an exploration into teacher educators' knowledge about assessment as a way toward an agreed basis to ensure the alignment. Third, award-winning teacher educators, as being professionals and presumably assessment literate, provide us ideal examples to explore how knowledge about and pedagogical understanding of metacognition interact with conception of assessment within assessment literate individuals, and ultimately direct assessment efforts to promote genuine learning benefits, which would shed lights to problematic situations where teachers are striving to become assessment literate.

\section{Teachers' Conceptions of Assessment}

Teachers hold knowledge, beliefs, belief systems, and belief clusters to make sense of events, people, and interactions (Pratt, 1992; Ekeblad and Bond, 1994). A wide variety of language has been used to address these complex mental structures, including "teachers" subjectively reasonable beliefs' (Harootunian and Yarger, 1981), "untested assumptions" (Calderhead, 1996), and "implicit theories" (Clark and Peterson, 1986), and "conceptions" (e.g., Pratt, 1992; Thompson, 1992). The term "conception" could represent a more general mental structure (Pratt, 1992), and acts as a framework, to represent different categories of ideas held by teachers to interpret experienced educational events and interacts with the teaching environment (Marton, 1981). Hence, teachers' "conceptions" is the term used in this study to describe the organizing framework, encompassing beliefs, meanings, concepts, propositions, rules, mental images, preferences, and the likes' (Thompson, 1992, p. 130), by which teachers understand, responds to and interacts with a educational phenomenon.

Exploring teachers' conceptions of assessment is important to understand the multifaceted and interconnected constructs within teachers' conceptions. $\mathrm{Xu}$ and Brown (2016) in their new conceptual framework of teacher assessment literacy in practice (TALiP) framework, consider teachers' conceptions of assessment as an important component of assessment literacy that interpret and guide teachers' uptake of theoretical knowledge and its implementation. In TALiP framework, conceptions of assessment, dependent on socio-cultural and institutional 
influence, consist of cognitive and affective aspects, and broader views of learning and epistemological beliefs. The cognitive dimension entails teachers' belief of truth and facility about assessment. It might decide what kind of new knowledge, idea, and strategies of assessment the teachers tend to uptake. The affective dimension relates to emotional dispositions, arising from various past assessment experiences (Crossman, 2007). TALiP interprets and explores conceptions of assessment by offering a dynamic ecosystem involving complex and important entities closely relate to assessment literacy, but still open to different contextual constraints and affordances. This openness sets it as an overarching framework for constructing teachers' conceptions of assessment.

In particular, three works are reviewed to develop a better understanding of the dimensions of teachers' conceptions of assessment. Delandshere and Jones (1999) proposed three dimensions to recognize and analyze teachers' conceptions on assessment, including (a) purpose and functions of assessment; (b) teachers' perception of curriculum and their professional self-efficacy feeling; and (c) their beliefs about the teaching and learning process and about students as learners. This framework specifies how cognitive and affective aspects are framed by broad views of teaching and learning and teachers' epistemological beliefs as proposed by $\mathrm{Xu}$ and Brown (2016). For example, teachers' perception of curriculum and their professional selfefficacy feeling is an example of affective dimension.

Research into teachers' conceptions of assessment has focused on purposes or intentions underlying assessment practices. Brown (2004) proposed four major purposes by synthesizing and reformulating key literature on assessment literacy: (a) assessment improves teaching and learning; (b) assessment makes students accountable for learning; (c) assessment makes schools and teachers accountable; and (d) assessment is irrelevant to the work of teachers and the life of students. Researchers have suggested that the development of assessment literacy might depend on teachers' conceptions of assessment. The understanding of both accountability and learning purposes of assessment as an assessor may enable teachers to take ownership of assessment practice, to initiate greater autonomy and to create more chances for their assessment literacy to be recognized (Wyatt-Smith et al., 2010). As higher level of assessment literacy is associated with more positive attitudes toward classroom assessment (Quilter and Chester, 1998; cited in Brown, 2008), Brookhart (2002) suggested classroom assessment to be prioritized over large-scale assessment in the knowledge base. While the failure or difficulty in improving assessment literacy may attribute to teachers' purely administrative conceptions of assessment [e.g., (b) making students accountable for learning; (c) making schools and teachers accountable] or negative view toward assessment [i.e., (d) assessment is irrelevant], greater commitment to improvement purposes [i.e., (a) assessment improves teaching and learning], however, could bring higher levels of assessment literacy (Brown, 2008).

Another model for conceptions of assessment functions was proposed by Remesal (2011), dealing with aspects: (a) assessment effects on learning (b) assessment effects on teaching (c) assessment effects on the certification of learning and (d) assessment effects on the accountability of teaching. This model is a good supplementary to Brown's model but is distinct from Brown's in two ways. First, Remesal's four-dimension model is weighing to a lesser or greater extent to either of two poles of assessment functions, either pedagogical or societal-accrediting. Second, Remesal's model views the way in which assessment affects teaching and learning differently, so the component of “assessment improves teaching and learning" in Brown's model is further divided into "assessment as a tool for improvement of teaching and assessment as a tool for improvement of learning."

An analytic framework proposed by DeLuca et al. (2013) identify four dominant conceptions of assessment; they are (a) assessment as testing, (b) assessment as format, (c) assessment as purpose, and (d) assessment as process. This framework increases in complexity by delineating assessment as format and process and connecting together assessment as, for and of learning. The conception of format expands the association of assessment with testing to alternative forms such as authentic assessment, taking into consideration of their applicability to "real-world" experience (Bartz et al., 1994) and focusing on higher order thinking skills that enable students to construct responses and assert reasoning. The conception of assessment as process views assessment as an essential component of teaching need to be integrally connected with curriculum and learning (Brookhart, 2011), thus fundamentally making judgments about learning on the basis of evidence to illustrate this conception, Brookhart (2011) modified the 1990 Standards for Teacher Competence in Educational Assessment of Students, stressing the integration of assessment data to inform teaching and learning. These standards raises an awareness of the limited scope of various assessment methods regarding the specific context of teaching and learning (DeLuca et al., 2013) and demonstrated the need to relate assessments to students' and teachers' classroom experiences.

Building upon the five reviewed theoretical frameworks, a synthesized analytical framework of teachers' conceptions of assessment is presented (See Figure 1). While the synthesized framework does not provide a comprehensive framework that accounts for all conceptions of assessment, they do highlight several dominant ones that drive teacher practice. Research suggests that teachers engage these multiple conceptions of assessment to various degrees, and their conceptions increase in

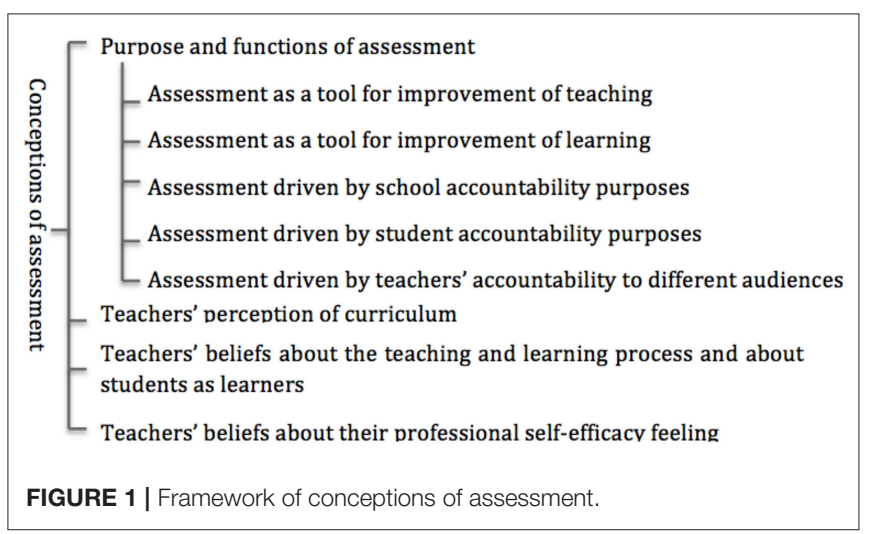


complexity, representing a progression from a singular emphasis on assessment as testing to a fully integrated understanding of assessment in teaching and learning processes (DeLuca et al., 2013).

\section{Framing Conceptions of Metacognition}

The notion, conceptions of metacognition, denotes knowledge of metacognition and pedagogical understanding of metacognition. Knowledge of metacognition includes general theoretical understanding of the definition of metacognition and the personal ability to practice metacognitive thinking with respect to classroom activities (Zohar and Barzilai, 2013).

For the components of metacognition (see Table 1), the present paper follows seminal work Brown's (1987) dichotomy, and addresses primarily knowledge of cognition, also known as metacognitive knowledge, which views human thinkers' own cognitive processes as objects of thought and reflection. We further categorize metacognitive knowledge by Flavell's framework into knowledge of self, task, and strategy (Flavell, 1979). In this paper, metacognitive knowledge refers to the knowledge one retrieve from their acquired knowledge basei.e., what they know or believe about themselves and others as cognitive beings (self) - in relation to various cognitive tasks (task) and strategies, as well as the experiences s/he has had in relation thereto. There have been different interpretations of metacognition amongst teachers. From the reviewed literature about teacher education, reflective thinking or reflective teaching is the most frequently mentioned aspect in relation to teacher's understanding of metacognition. Wen (2012) succinctly summarized that a metacognitive teacher should be aware of:

TABLE 1 | Theoretical framework of metacognition.

\begin{tabular}{|c|c|c|}
\hline $\begin{array}{l}\text { Metacognitive } \\
\text { component }\end{array}$ & Type & Terminology \\
\hline \multirow[t]{10}{*}{$\begin{array}{l}\text { Cognitive } \\
\text { knowledge }\end{array}$} & \multirow[t]{4}{*}{$\begin{array}{l}\text { Knowledge about oneself and } \\
\text { factors affecting cognition }\end{array}$} & $\begin{array}{l}\text { Inter-personal/intra-personal } \\
\text { knowledge }\end{array}$ \\
\hline & & Intra-personal knowledge \\
\hline & & Self-appraisal \\
\hline & & Epistemological understanding \\
\hline & \multirow{3}{*}{$\begin{array}{l}\text { Task awareness and task } \\
\text { interpretation }\end{array}$} & Task purpose \\
\hline & & Task structure \\
\hline & & Task demands \\
\hline & \multirow{3}{*}{$\begin{array}{l}\text { Awareness and knowledge } \\
\text { about when and how to use a } \\
\text { given strategy }\end{array}$} & Procedural knowledge \\
\hline & & Declarative knowledge \\
\hline & & Conditional knowledge \\
\hline \multirow[t]{3}{*}{$\begin{array}{l}\text { Cognitive } \\
\text { regulation }\end{array}$} & $\begin{array}{l}\text { Identification and selection of } \\
\text { appropriate strategies and } \\
\text { allocation of resources }\end{array}$ & Planning \\
\hline & \multirow{2}{*}{$\begin{array}{l}\text { Attending to and being aware } \\
\text { of comprehension and task } \\
\text { performance } \\
\text { Assessment the processes } \\
\text { and products of one' learning, } \\
\text { and revisiting and revising } \\
\text { learning goals }\end{array}$} & $\begin{array}{l}\text { Monitoring or regulating } \\
\text { Cognitive experience }\end{array}$ \\
\hline & & Evaluating \\
\hline
\end{tabular}

his/her self or the students' thinking (person variables); the differences in partial knowledge for teaching, and its different types of cognitive demands (task variables); and, cognitive and metacognitive strategies (strategy variables) to enhance student's learning and performance.

The pedagogical understanding of metacognition refers to teachers' knowledge regarding effective instruction for teaching students to be metacognitive (Wilson and Bai, 2010), including knowledge of how to scaffold and guide students, how to demonstrate thinking, knowledge of strategies, knowledge of students, and knowledge of when to implement strategies (Gourgey, 1999). Teachers' understanding that students need models of strategies in action to guide their own practice in teaching practice (Clark and Graves, 2005), is one example of teachers' pedagogical understandings of metacognition that includes instructional strategies.

\section{Connections Between Assessment and Metacognition}

The connections between assessment and metacognition have been well-articulated in a number of articles (e.g., Andrade, 1999; Earl, 2003; Panadero et al., 2013). Three major ways of interaction are found by reviewing these studies: practices of assessment for learning (AfL) as ways to develop autonomous learners (e.g., Rogoff, 1995; Pryor and Crossouard, 2008); selfassessment as a regulatory process in metacognition (Andrade, 1999; Earl, 2003; Panadero et al., 2013); and shared features between authentic assessment and metacognition (Andrade, 1999). First, AfL practices are perceived as a form of guided participation as learners are apprenticed toward autonomy. Participation functions an importance role in AfL as it offers the potentials for cognitive development through social interaction with more experienced others as a form of guided participation or apprenticeship (Rogoff, 1995). Second, the purpose of selfassessment, as claimed by Andrade (1999), is to promote metacognitive engagement. It is perceived as a regulatory process in metacognition when students stand back and reflect upon the products and process of their work, assuming an active, engaged, and critical role to make sense of information (Earl, 2003). Third, authentic assessment, exemplifying the real-life behaviors and challenges experienced by actual practitioners in the field (Hawkins et al., 1993), encourages students to become "autonomous and self-regulating adults, capable of judging the success of their own endeavors" (Haney, 1991, p. 154). Andrade (1999) compared the key characteristics of effective instruction in metacognition and authentic assessment for comparison and found them shares many similarities, e.g., students' scaffolding in their own efforts to learn, and assisted in making accurate and constructive self-assessments.

Three additional issues related to assessment practices are found to connect with metacognition. First of all, productive feedback promotes self-regulated learning by informing students about grading tactics and strategies that process domain-specific information (Butler and Winne, 1995). The frequency and characteristics of feedback would impact on students' selfefficacy. For example, students increased the more self-efficacy when receiving feedback on process rather than on performance 
(Panadero et al., 2012). Second, a study by Panadero and Jonsson (2013) shown that rubrics and self-assessment scripts would enhance student performance and learning when integrated into metacognitive activities. Specifically, students using script had higher level of learning self-regulation when compare to the rubric and the control, and that the rubric group had higher level than the control. Third, modeling as instructional technique in AfL is also shown to be an important metacognitive tool that benefits students' metacognition through the process of observing an expert modeling a desired behavior or outcome (Panadero and Jonsson, 2013).

Despite the compelling theoretical evidence revealing the connections between assessment and metacognition, many teachers are often involved in assessment decision-making without sufficient awareness of students' metacognitive development that has already been well-acknowledged to be crucial for learning (De Backer et al., 2012). It would be regrettable when teachers may spend about a half to a third of their professional time on assessment-related activities (Stiggins, 1995), yet they neglect the metacognitive elements in teaching and learning associated with assessment. While literature has revealed some theoretical relationships between assessment and metacognition, yet how teachers actually perceive the link is still unknown. Therefore, researching on how conceptions of metacognition interact with and direct conceptions of assessment to improve students' learning and the quality of teaching is intriguing as it is a good departure point for further examining teacher assessment literacy from a metacognitive perspective so as to offer an alternative dimension to interpret and understand what it entails.

\section{METHODS}

This multiple case study is framed by the following three research questions:

RQ1: What are the case teachers' conceptions of assessment?

RQ2: What are the case teachers' conceptions of metacognition?

RQ3: How did the three case study teachers perceive integration between metacognition and assessment?

\section{Context and Participants}

Three teachers were selected by observing their classes and examining their suitability against the criteria listed above. My rationale for sampling award-winning teachers was that they may exemplify one or more of the following features, as suggested by Carless (2015): high-quality teaching and learning practice; student-centered teaching, or teaching strategies that are attractive to students; and innovative or provocative practices. I assumed it would be more likely to find good, or potentially good assessment practices in relation to metacognition amongst these teachers, than amongst other groups. An additional pragmatic consideration was that award-winning teachers are more willing to participate in a study of their pedagogy, and their commitment to their students makes them a particularly worthwhile site for research.
Three teachers, pseudonymously called Nancy, Megan, and Jason, were involved in the study, and they all received a teaching award by the university in Hong Kong. Nancy had over 24 years of teaching experience, and teaching and students' empowerment have always been her top priorities, and she has keenly monitored her students' personal and pedagogical growth, during and after her course, and beyond graduation. She considered students to be co-learners, and helped develop a collaborative learning community among them, to foster team spirit. Her research interests encompassed all areas of teaching, including teachers' development and the impact of teaching pedagogies on students' learning. The cohort of students involved in this study were 26 final-year undergraduates enrolled in a 5-year double degree BA/BEd programme, jointly offered by the Faculty of Arts and the Faculty of Education. A facilitating factor in selecting this cohort was that Nancy had taught this group of students for 2 years; thus, she was quite familiar with their abilities, needs, and characteristics, trusting relationships had been established.

Megan had profound teaching experience for young learners as well as for teacher training. She used to teach at the British Council, overseeing the Young Learners Division, and at the same time ran a teacher training course. At the time of the study, she had taught many ELT pedagogy courses in different programmes. She received a faculty award for teaching excellence, and her teaching expertise focused on ELT pedagogy and English literacy. With research interests in English language education and teacher development, she has directed or participated in several research projects exploring Hong Kong English education in Primary and Secondary settings. The study involved Megan's Year 2 cohort of undergraduate students enrolled in a 4-year BEd in Language Education programme.

Galvin had majored in English language, and minored in Literature. He had profound experience in teaching young learners, and in teacher training. His work experience in the local community informed his teaching at the University. He believed teachers can and do make a difference every single day, and so sought to promote, in his student teachers, a sense of appreciation and awareness of the transformative role they can play in classrooms. At the time of study, he taught approximately eight cohorts of students enrolled in Postgraduate Diploma in Education (PGDE) programme, which prepares graduates to teach in Hong Kong.

\section{Data Collection}

This study was part of a larger project on assessment and metacognition. A variety of data collection methods were adopted in this project, including observation, think-aloud protocol, stimulated recall interview, semi-structured interview, and document analysis. Due to the foci on teachers' conceptions of assessment and metacognition, the primary data used for this study were classroom observation of teachers and interview data with the three case teachers, supplemented by teacher-produced document analysis. Other sources of data on student cases are equally worthwhile, but they were collected and analyzed to address other research questions as part of the larger research project (The whole dataset is presented in Appendix A).

Perceptions are based on experience and are often expressed through statements; given that beliefs are not directly observable, 
(Kvale, 2001) propose sustained interviews or conversations as a reasonable method. In this study, a total of five semi-structured interviews, each with duration between $40 \mathrm{~min}$ and $1 \mathrm{~h}$, were conducted with case teachers in which three interviews were carried out with Nancy, one with Megan and one with Jason. The data collection for Nancy's case was one year ahead of Megan and Jason' case due to case teachers' teaching arrangement. The first interview with Nancy was part of the pilot study taking place at beginning of the first semester. The second interview was carried out by the end of the first semester, and the third interview took place during the second quarters of the second semester. The first semi-structured interview with Nancy addressed topics such as the characteristics of assessment and its relationship with teaching and learning, routine assessment practices in her classrooms, and interpretation of metacognition. The themes of first interview prompts were majorly derived from the literature review whereas the prompts for the second semi-structured interview came from pilot study, preliminary findings from classroom observation and document. The third interview for Nancy had a more open structure, with just a few prompts to let teachers comment on the materials I brought in, and clarify some statements she had made in the previous two interviews (see Appendix B). By the time of conducting interview with Megan and Jason, the interview protocols had experienced three rounds of modifications. The changes including refined questions with the right wording, better choice questions in a logical sequence and new insights from the provisional interview protocols.

Classroom observation was another essential method of data collection in this study. The classroom observation followed a process-oriented and descriptive approach. The emerging issues observed in the class will aid the subsequent interview so as to probe teachers comments and reflections about the underlying conceptions of assessment and metacognition. The classroom observation covered two academic semesters in Nancy and Megan case, a total 18 and $16 \mathrm{~h}$ were observed, respectively. Eighteen hours of Jason's course were observed over one academic semester. The observation instrument adopt the observation scheme designed by Carless (2010) in his investigation of how teachers conduct test follow-up lessons. It was further developed and enriched by referencing the data collection instruments used by Estacion et al. (2004). The main aim of the observation instrument was to set up a user-friendly means of recording classroom activities relevant to teachers' conceptions of assessment. The instrument needed to be dualfaceted-concise enough to be used effectively in the classroom, but detailed enough to be used comprehensively in later analyses. The observation instrument consisted of three parts: general information with close-end, low-inference items about time, place, teacher name, and lesson topic; a Running Record Form to provide a detailed account of activities taking place in the classroom; and, an open space for recording emerging issues (see Appendix C).

The ethical protocol was approved by Ethics Committee of the University of Hong Kong. All participants gave written informed consent in accordance with the Declaration of Helsinki. In this section, three case teachers' general educational background, teaching philosophy, and past teaching experiences were introduced. I still think these information are helpful and necessary for the following two reasons: first, the introduction of case teachers provides necessary background information for readers to understand the conceptions and beliefs about teaching, about assessment and about metacognition, as well as to decide the extent to which the insights drawn from reading the study could shed to their own. This consideration closely relates to the concept of "dependability." Being a qualitative study, this study seek variations in experience (Merriam, 2001), however, variability should be presented in a trackable way and be ascribed to identified sources (Guba and Lincoln, 1981).

Second, while this study tried to depict the background as detailed and relevant as possible, the personal information of three case teachers are carefully handled. First of all, the names of the teachers are pseudonyms, the exact name of the faculty and the university are concealed. Other than that, additional information about the three case teachers presented in the study (education background, teaching experience, etc.) are in fact not sensible to them, because being award winning teachers, they were willing to share their teaching philosophy with wider audience. Their profiles shared here are education-informed, pedagogy-related and non-sensitive, partly drawn from their public profile website, and partly from interview data. The data followed accepted ethical procedures and were agreed to present for research purposes.

\section{Data Analysis}

The data analysis passed through two phases. In the first phase, the interviews with teachers were all transcribed verbatim, and then parsed into meaningful units. These units were analyzed and categorized against two initial analytical frameworks (see Figure 1 and Table 1). To address the first research question, the aforementioned synthesized frame of conceptions of assessment was adopted for analyzing teacher's conceptions of assessment (see left column of Table 2). The analytical framework to address the second research questions is based on a synthesized

TABLE 2 | Coding scheme for RQ1 and RQ2.

\begin{tabular}{ll}
\hline Codes for assessment & Codes for metacognition \\
\hline Purpose and functions of assessment & $\begin{array}{l}\text { Inter-personal/intra-personal } \\
\text { knowledge } \\
\text { Intra-personal knowledge }\end{array}$ \\
As a tool for improvement of teaching & Self-appraisal \\
School accountability purpose & Epistemological understanding \\
Student accountability purpose & Task purpose \\
Teacher accountability purpose & Task structure \\
Teachers' perception of curriculum & Task demands \\
Teachers' beliefs about the teaching and & Procedural knowledge \\
learning process and about student as & Declarative knowledge \\
learners & Conditional knowledge \\
Teachers' beliefs about their professional & Planning \\
self-efficacy feeling & Monitoring or regulating \\
& Cognitive experience \\
& Evaluating
\end{tabular}


framework of two seminal works, Brown (1987) and Flavell (1979) (see right column of Table 2).

In the subsequent round coding, potential pertinent and salient issues that went beyond the aforementioned two coding schemes were emerged as codes for research question one and two. By this time, the data were analyzed majorly in a qualitative and inductive manner to identify, categorize and explore main themes for the research questions three. The documentary and observation data were analyzed against the data from interviews, and were compared for triangulation, so that codes would emerge across all three sets of data in the initial round. All the data went though content analysis from initial coding to focused coding (Miles and Huberman, 1994). This process was grounded and iterative, with new codes emerging, and existing codes revised and aggregated, when the transcripts were read and reread. Examples of the categories included teachers' expectations; judgment of self-efficacy for task, judgment of self-efficacy as teacher, awareness of EFL students needs. Finally, the refinement of codes was developed through negotiation between the author's supervisor, and a critical peer of the same discipline, to ensure the reliability of interpretations and to bring reflexivity into the process. The data analysis process was aid by the software NVivo which helped with organizing and analyzing the data and provided a means of drawing insights from unstructured and multiple-sourced qualitative data, and made the connections between the data more visible.

\section{FINDINGS}

\section{Nancy's Case: Overview of Assessment Design}

The course under study was a compulsory course titled Pedagogy III, which is the final in a series of three courses, spanning Years 2, 3 , and 4 . The course is designed to build on and expand students' knowledge of the pedagogical issues learnt in their earlier years. Specifically, Pedagogy III aims at developing students' ability to design, adapt, and sequence a lesson by formulating and enacting a better understanding of the NSS curriculum, develop a critical perspective on the procedure, and become aware of the critical role they, as teachers, play in education.

TABLE 3 | Overview of assessment tasks in Nancy's case.

\section{COURSE REQUIREMENT AND ASSESSMENT}

Hurdle requirement

Student-led seminars

Microteaching

Major assignment
Quality dialogue with their coursemates in their Moodle discussion (three entries minimum)

Group presentation, discussing major themes of NSS

Teaching a 25-min lesson, integrating themes of NSS

1. Lesson planning

2. Reflection on the two taught lessons in the unit of work

3. Rationale

4. Reflective report
A complex set of course requirements and assessment were designed (see Table 3) consisting of one major assignment, with five requirements: (1) plan a lesson for a unit, comprising a sequence of four connected lessons for their teaching practicum (TP); (2) select two lessons to teach; (3) write a rationale for the two lessons taught, citing the relevant literature; (4) complete a self-reflection report on the planning and implementation of the two taught lessons; and (5) articulate their personal knowledge in practice.

\section{Nancy's Conceptions of Assessment and Metacognition}

In the interview, I probed Nancy's conceptions of assessment, and she offered the following perspective:

\begin{abstract}
(Assessment) is developmental, it is ongoing, it is inevitably formative, we did not think of the word, formative, because we think it is too general... we didn't want there to be only one assessment, even if it were one final task at the end; we wanted them to learn from the earlier experience, so that they could do better in the next one, and they can realize the feedback that they get would contribute to like a better performance. Performance was not the key things that we were looking for, we were looking more for their reflection, based on our given feedback and they found the feedback useful (1st Interview_N).
\end{abstract}

I would say, in the notion of assessment for learning, basically everything in the course is formative, because it is meant to be supportive and its nature is meant to provide them with feedback. It's all invitational in terms of, like, when it comes to any point in time, if they would like a discussion. I think when I am thinking how I could structure the course, like what should be put in session 1 and session 2, it relates very much to what I hope they could build on, based on earlier sessions and what they can get; for example, the micro-teaching has reinforced what they have learnt previously and the guest teacher like wise (1st Interview_N).

Here we can see the enactment of some of the elements Nancy was trying to promote through assessment: "developmental," "formative," "assessment for learning," "invitational," and "supportive." Thus, the overarching aim for the assessment resonated with the notions of assessment for learning. The task design needed to be formative and developmental, such that the assessment tasks "could be built on, based on earlier sessions and what students can get." The assessment approach was invitational and supportive, in that students could ask questions and reflect upon the feedback received. This aligned with Nancy's understanding of metacognition as students' ability to reflect.

When asked about metacognition, Nancy seemed to have thought about it a great deal:

I relate metacognition to two keys: one would be their thinking back, looking back, reflecting on anything, like for example, reflecting on the reading at a critical level, reflecting on their own teaching, and problematizing things, acting on, for example, feedback that they receive and respond to different things; the second notion would be similar to, critical thinking (1st Interview_N). 
In this quotation, Nancy succinctly summarized her knowledge of metacognition into two aspects: reflective thinking, and critical thinking. She further illustrated two concrete examples:

\begin{abstract}
I think that has led me into asking, in class and outside class and on emails in response to assignment, a lot of questions. Questions about things they have said, for example, they could elaborate on things that they have said which can be concretized, things which they have taken for granted, just getting them into different perspectives. I am just thinking about what I do in the classroom, like say for example, if they talked about, let say there is problem, and there is solution. Maybe everyone agrees on one major solution, I may get them to think back what are the alternatives to that solution. For example, whether they have a different ability group, how would they deal with it, how would they deal with different ability students where they have different ranges of strategies to cage for something (1st Interview_N).
\end{abstract}

Nancy related metacognition to awareness of different perspectives and alternative solutions. In other words, Nancy's interpreted metacognition as a variety of knowledge of cognition-awareness of one's own cognitive strategies and others' relevant to being a student-teacher and to their future careers.

Table 4 summarizes the keywords from Nancy's perceptions of assessment and metacognition. It is apparent that, although the terminology is different, many terms are related to each other. It seems that in Nancy's perception assessment should closely connect with metacognition. This is evidenced from my further probing that the extent to which she connected assessment task design with metacognition. Nancy explicitly pointed out that, "it is everything." Some representative quotations illustrating her perspectives as follows:

I guess we tried to, definitely, yes, but at the same time, we think we try to keep the tasks open to such an extent, that because students' assignment would all be related to teaching practice. And during teaching practice, there were variations in terms of what schools

TABLE 4 | Nancy's conceptions of assessment and metacognition.

Conceptions of Conceptions of metacognition
assessment

Developmental, on-going, formative

Supportive feedback contributing to a better performance

Invitational and probing

In context (authentic)

Not focusing on academic performance

Self-evaluation opportunities
Reflective thinking: ability to thinking back (cognitive regulation)

Reflection based on given feedback (cognitive regulation)

Thinking from different perspectives

Problematizing things (conditional and procedure)

Thinking alternatives to solutions (declarative and conditional)

Critically reflecting on assessment process (cognitive regulation)

Reflexive and critical thinking (Self-appraisal and cognitive regulation)

allow them, or don't allows them to do. So, we try to keep it open to an extent, where, for example, if they are required to be using a textbook in the school, how can they critically evaluate it, or if they were given more autonomy to develop their own materials, how can they also reflect on them (1st interview_N).

We wanted them to benefit from the feedback, and to realize that this is something that would help them in their microteaching. The feedback that they get from the microteaching and the experience that they get from the microteaching would help them in their final assignment. And we think, overall, the things we did involved critical elements and involved reflexive elements (2nd interview_N).

Such comments about assessment design are congruent with Nancy's understanding of metacognition as being "critical" and "reflexive." We can see that her pedagogical understanding of metacognition regarding assessment related to two major areas: task and feedback. The assessment tasks, according to quotation one, were designed to be closely related to teaching practice, to engage students in critically evaluating and reflecting on what they have done in their teaching practice, which relate closely with students' regulation of cognition. Feedback was another important consideration in assessment design, and one through which is supported to better performance in a selfregulated manner. However, it seems that although Nancy hoped for a better performance (accountability) from students, she attached more weight to learning process. This is reflected in her perception of metacognition which closely relates to declarative and procedural knowledge of strategy in tackling the assessment tasks.

\title{
Megan's Case: Overview of Assessment Design
}

This was a 12-credit, 18-week core course, titled "Learning and teaching the spoken and written language in the early primary years," intended to develop students' skills, confidence, and creativity in lesson planning, task design, and teaching strategies for teaching English to children at the KS1 level (primary 1-3) in Hong Kong primary schools. Assessment for the course involves three main elements, summarized in Table 5. The first task involves a lesson plan for a 20-min micro-teaching project (MT); the subsequent reflective report is the second task, while the final task is an "all-in-one" written work on a lesson conducted in teaching practicum (TP).

TABLE 5 | Overview of assessment tasks in Megan's case.

\section{COURSE REQUIREMENT AND ASSESSMENT}

Lesson planning

Reflection

Lesson study
Collaborative planning of a lesson for lower primary students and explaining the principles and theories underpinning it, presented on a Wiki.

A critical reflective analysis of the microteaching lesson.

Planning, implementation, and critical analysis and reflection on a grammar-focused lesson taught during TP. 


\section{Megan's Conceptions of Assessment and Metacognition}

In the interview, the Megan succinctly expressed her beliefs about assessment:

\begin{abstract}
I guess the assessment should be highly, deeply related to what is being taught. There should not be any disconnection there. It should engage students in reflective practice as much as possible and get them to engage with the theories. And then it should be as authentic as possible. And then it should lead them to be better teachers, not just jump through the universities. But what I am hoping, is that students could learn from it and become better teachers. That is the result. That is the most important thing (Interview_M).
\end{abstract}

Megan understood assessment to have four requirements. First, designed assessment tasks should be relevant, and closely related to what is being taught. Second, assessment should engage students, not only with the theories they need to learn, but (most important) in reflective thinking. Third, assessment tasks must be authentic. Finally, assessment should direct students' learning efforts, and ultimately lead to their becoming a better teacher.

When I asked Megan what students' metacognition meant to her, she replied,

For my students, I want to get them be reflective teachers, so I would like them to be quite aware of their actions in the classroom and their beliefs and principles, or even just their personal history, and how that influences what they do, what they say, and how they think. That is kind of ultimately a high level of self-awareness and being able to step out of yourself, and being quite conscious of your own beliefs and principles. I think that it is quite healthy for teaching, because it means that you can change and that you can understand the context of, you know, why you made that decision; maybe it contradicted with what you read or what you had been taught in class (Interview_M).

It seems Megan had two different interpretations of metacognition, as she seemed to see two roles for her students: being a student in a university training course, and being an EFL teacher in a future primary language classroom. For former, she interpreted metacognition as "strategic awareness" of different learning contexts. She offered a grammar learning experience as an example.

Like, grammatically, if you want them to have grammatical awareness, you want them to have awareness of their learning strategies, you want them to be ready for their written assignment, and how they think about, you know, how to plan the assignment; that is a part of metacognition as well (Interview_M).

In this extract, she emphasizes students' need for strategic awareness of their assignment, including how to plan, and what strategies to use to get ready for the assignment, which alludes to an element of MK, the knowledge of strategy.

However, Megan emphasized her goal for her students was "to get them be reflective teachers." From this perspective, she perceived metacognition was a "kind of ultimately high level of self-awareness, and of being able to step out of yourself, and being quite conscious of your own beliefs and principles." This description encapsulates quite neatly the notion of metacognition, but centralizes students' knowledge of self. She went on to list several facets of what she meant by "awareness."

To be quite aware of their actions in the classroom and their beliefs and principles, or even just their personal history, and how that influences what they do, what they say, and how they think (Interview_M).

This extract shows Megan's understanding of multiple facets of metacognition. The central focus of her interpretation seemed to be students' inter-individual understanding of self, such as awareness of one's own believes, principles, personal history, etc. She also included procedural knowledge of how things happen. In fact, a more comprehensive understanding of metacognition is reflected in her description of how this awareness could be "healthy for teaching:"

I think that it is quite healthy for teaching, because it means that you can change and that you can understand the context of, you know, why you made that decision; maybe it contradicted with what you read or what you had been taught in class, but you did it because you went to a school like this or because you knew whatever reason, or because this would happen in class. This was my own personal experience (Interview_M).

This extract captures Megan's understanding of multiple facets of metacognition, such as conditional knowledge of different contexts and why some decisions to change were made (first two sentences), and the ability to recall one's "personal experience" to justify a decision.

Overall, in these extracts, Megan identified and referred to several aspects of metacognition (summarizes in Table 6), by considering the different roles played by students. Although she had not used metacognition terminology directly, she had touched on several metacognitive elements. For students who were taking the training, she referred to metacognition as a strategic awareness of strategies for dealing with different learning contexts and tasks-i.e., knowledge of strategy. More important were her expectations that her students become reflective teachers, in which case, she viewed metacognition as a higher level of self-awareness, of being able to step out of

TABLE 6 | Megan's conceptions of assessment and metacognition.

\begin{tabular}{|c|c|}
\hline $\begin{array}{l}\text { Conceptions of } \\
\text { assessment }\end{array}$ & Conceptions of metacognition \\
\hline Highly relevant & Awareness of personal history (Person) \\
\hline Engaging with theories & $\begin{array}{l}\text { Knowing why contradicted with what you read or } \\
\text { what you had been taught in class (declarative and } \\
\text { conditional) }\end{array}$ \\
\hline $\begin{array}{l}\text { Engaging with reflective } \\
\text { practices }\end{array}$ & $\begin{array}{l}\text { Be quite aware of their actions in the classroom } \\
\text { (Person) }\end{array}$ \\
\hline In context (authentic) & Understanding the (teaching) context (conditional) \\
\hline $\begin{array}{l}\text { Leading to better } \\
\text { teachers }\end{array}$ & $\begin{array}{l}\text { Conscious of ones' teaching beliefs and principles } \\
\text { (person) }\end{array}$ \\
\hline $\begin{array}{l}\text { Accountability of } \\
\text { students }\end{array}$ & $\begin{array}{l}\text { Thinking how to plan the assignment to get good } \\
\text { grade (procedural) }\end{array}$ \\
\hline Self-evaluation & Reflection (Self-appraisal and cognitive regulation) \\
\hline
\end{tabular}

opportunities 
oneself, being conscious of one's own self-knowledge (beliefs, principles, and personal experience and history), and having declarative and conditional knowledge of strategy (when and why to make changes, according to different teaching contexts), which seems to indicate a sound grasp of the multi-faceted nature of metacognition.

Major keys words summarized in Table 6 present a good alignment of the two conceptions. This is evidence from Megan's words that her overall assessment task designs were "meant to develop them metacognitively." From her above-mentioned beliefs of metacognition, I see two foci, each oriented toward a different level of teacher's interpretation of metacognition (see Table 1). First, Megan emphasized that tasks need to be "highly relevant to what we've learnt" and "as much as possible to get them to engage with theories," which would ask more about students' "strategic awareness" to meet course requirements. This intention is quite salient in the following expression:

I want them to get a good grade on this course. I want them to understand how to do the assignment... so, of course, the better they did the assignment, the better I think they learnt (Interview_M).

Another focus was preparing students to be reflective teachers, by engaging with reflective practices, emerging in authentic tasks and contexts, and ultimately leading to becoming a better teacher. Megan saw the important role of students as future teachers, which likely enacted her interpretation of metacognition as highlevel self-awareness; as she put it, "I believe that the assignment helped them to learn and become better teachers."

However, Megan also confessed, in the interview, that in her actual teaching she was concerned more about teaching itself, e.g., covering certain content, syllabus items, topics, etc. She believed metacognitive awareness could be developed through engagement.

When I teach, you know, sometimes my concern is really more about actually needing to cover some content. I really have to cover the syllabus, the topics that I think they need for teaching in schools, and then I try to do it in a way that, let them to engage with it actively. I try my best and sometimes it is very boring and sometimes it is not very active. My belief is, the more they personally engage with what I am teaching-maybe it is the topic of teaching grammar, or teaching speaking skills or whatever-they should be trying to be engaged with it directly, so that their awareness of their own belief and, you know, they own experience, comes out in the process (Interview_M).

In sum, Megan believed assessment should be relevant, engaging, authentic, and lead to the student becoming a better teacher. As her overall assessment design was based on those beliefs, that meant was intended to develop students' metacognition. There were two foci embedded in her four beliefs, each directed to her different interpretations of metacognition.

\section{Jason's Case: Overview of Assessment Design}

Jason's course was an elective intended to raise awareness of different literary genres, and provide students with literary techniques and basic methodological strategies for teaching English literature. The module comprised nine interactive
TABLE 7 | Overview of assessment tasks in Jason's case.

\begin{tabular}{ll}
\hline COURSE REQUIREMENT AND ASSESSMENT \\
\hline Hurdle requirement & $\begin{array}{l}\text { Sharing of imaginative texts and discussion on how } \\
\text { to exploit them in the respective TP classes } \\
\text { 2,000+ words long, critically examine, and analyze } \\
\text { a self-selected literary text }\end{array}$ \\
&
\end{tabular}

lectures, each $2 \mathrm{~h}$ in length. The assessment for the course involved two elements, summarized in Table 7. The first task involved collaborative sharing; the major task was a written essay.

\section{Jason's Conceptions of Assessment and Metacognition}

Jason described himself as "a big believer in interactive assessment," then elaborated on what he meant:

Assessment is done through questioning, is done through checking, is done through probing; through daily interaction with students. I am a big believer in it. I would never set a quiz, I would never set an exam, I would never do anything like that. So, my way of assessing is purely through daily interaction with students. I can see if they find it difficult, I can see if they enjoy it, I can see if they want more or they want less. So, a lot of it is interactive nature of the class (Interview_G).

The way Jason assessed students emphasized the interactive nature of class, through, for example, classroom questioning, in-time probing, and daily communication with students. A further principle underpinning Jason's assessment practice was that of participation.

The assignment is not the most important thing for me. Participation in the class is more important, yes, the engagement. I can see what they have done with the course, what they talked, how they answer. So, those things mean more than the assignment (Interview_G).

It seems Jason valued classroom participation more than assignment, and observed students' participation very carefully.

\footnotetext{
I see the assessment part is a tricky one, because once you start to assess participation, meaning that you are giving a grade to students to answer, then it likely becomes difficult. I find that personally, I try it but I haven't been happy with the result, because my natural style in the classroom is to try to encourage students to response. If I say to them, all right, I am going to give you a reward every time you participate, it seems to be an extrinsic reason. You see what I mean? I want them to have an intrinsic reason (Interview_G).
}

In terms of assessment, Jason was not in favor of grading students' participation, which he considered an extrinsic reason for participation. Instead, he hoped to see more intrinsic motivation from students to participate in the class. This conforms to his practice of using interactive assessment to create a lively classroom atmosphere.

In the interview, I sought to understand Jason's interpretation of metacognition: 
The two (participation and metacognition) are concerned. To me, my view of the classroom is as a social context, participation is learning. I don't think there is any doubt when students are participating, whether it is thinking, whether it is talking, whether it is putting up their hands, whether it is acting like the other day, it is learning, it is doing. So, to me, the two are totally connected (Interview_G).

The notion of participation was central to Jason's thinking about metacognition. Jason referred to social theory, related metacognition to "participation," which he linked to "learning." His ideas resonate with the notions of metacognitive engagement, discussed in the previous chapter.

The following three quotations further clarify Jason's understanding of metacognition as metacognitive engagement.

So, engagement and participation don't only have to be verbal. Participation to me can be somebody paying attention, focusing, thinking, engaging, and metacognition. I can see if students are not listening, I can see if students are off the class. That is easy. But you can also see when they are paying attention or they are thinking, or even they are talking to their partners, when they are talking about something. So, to me, that is participation.

So, there is really about enjoyment, because I think everything goes back to engagement. If it is teaching, it has to be about, you know, through engaging, and then you tend to be remembering things and you learn. But I also feel that it is also about letting them take something away. It is about confidence and it is about awareness and it is about expectation, trying different things.

This is a PGDE class, so in terms of their outcome and the metacognition, it has to be more practical, because they are doing a PGDE program. If it is a Master's program, there will be more input in terms of the theoretical understanding, but because they are really thinking about it from a practical view point.

Three codes emerged from the above data, in terms of what Jason meant by metacognitive engagement- "participation," "enjoyment and confidence," and "remembering." In the first quotation, Jason made a clear connection between engagement and participation. In his understanding, participation was metacognitive engagement in ways of "paying attention, focusing, thinking." Paying attention, in his eyes, need not be verbal, but should be noticeably. This is exemplified in the following example Jason provided:

For example, Kerry and Ailsa and Angela. They wouldn't answer as many questions as the other students in the class, but that doesn't mean they were not engaged. I can see that. I can see if students are not listening, I can see if students are off the class. That is easy. But you can also see when they are paying attention or they are thinking.

In the second quotation, Jason pointed to how students felt and experienced matters as engagement; facilitating students' enjoyment of and confidence in learning is an important way of engaging students. In the third quotation, Jason emphasized that engaging is about "remembering things, and awareness of applying them in reality." This embraces two important aspects of
TABLE 8 | Jason's conceptions of assessment and metacognition.

\begin{tabular}{ll}
\hline $\begin{array}{l}\text { Conceptions of } \\
\text { assessment }\end{array}$ & Conceptions of metacognition \\
\hline $\begin{array}{l}\text { Interactive nature } \\
\text { Engaging }\end{array}$ & $\begin{array}{l}\text { Paying attention, focusing (cognitive regulation) } \\
\text { Metacognitive engaging } \\
\text { Informal feedback and } \\
\text { evaluative dialogue } \\
\text { Occurring within the } \\
\text { daily interaction in the } \\
\text { classroom }\end{array}$ \\
$\begin{array}{l}\text { Assignment is } \\
\text { unimportant }\end{array}$ & Thinking from a practical view point (conditional) \\
Safe and trust & Long-term benefits \\
\hline
\end{tabular}

metacognitive knowledge- "knowing that one is knowing" and "knowing how to apply."

Taking all the data into account (summarizes in Table 8), I infer that Jason related metacognition to students' metacognitive engagement, for which there were three indications: (1) participation, not necessarily verbal, but through at least noticeably paying attention; (2) metacognitive experience, enjoyment, and confidence; and, (3) metacognitive knowledge of strategy-i.e., knowledge and awareness of applying what one has learnt, in reality.

Jason was asked to generalize how his understanding of metacognition was enacted in his daily classroom practice.

So how I prepare my things, it is the same. I am going with the same idea. They have to be engaged, they have to be motivated, they have to be enjoying the course. Everything I do in class is designed to encourage a safe environment, an environment where they feel they can participate in any way they like.

Again, I hope there are some long-term benefits, like I can't use this in this TP, but I could use it in my future class. I hope this could live in their head, that literature is not an abstract concept, but is actually closely linked to language teaching. That's my goal.

Jason related teaching metacognitively to being able to engage students in class, and stressed that his aim was: (1) to create a "safe and non-threaten environment;" and (2) to raise students' awareness of, and build their confidence in applying the literacy teaching skills learnt to their own language teaching. Belonging, trust and respect was not regarded as peripheral to the learning work within the classes, but an essential social foundation that Jason tried to continually maintain so that students would engage in the risky process of negotiating teaching strategies of literature which they are not confident about. The teachers assumed an enthusiastic expert role to established positive relationships with students through humor, shared language and routines, movement throughout the class.

\section{DISCUSSION}

The purpose of the study explores how teachers' conceptions of assessment interact and work with conceptions of metacognition 
when making assessment decisions, and strives for theoretical implications to construction of teacher assessment literacy from a metacognitive perspective. Overall, the findings show that the integration was manifested in different ways between teachers' interpretations of metacognition and beliefs of assessment across the three case teachers, although to varying degrees; the extent and aspects of integration depended very much on how the interpretation of metacognition was embedded in assessment beliefs. Three case teachers' conceptions of task design and assessment methods were appropriate for instructional decisions, and students' metacognitive development was part of their pedagogical objectives. Their assessment objectives were subject to learning, and they perceived metacognition as an indispensible disposition of learning. These findings are consistent with the view that teachers' understandings of metacognition appears to be related to their conceptions of instructional strategies that assist students in to develop their metacognitive knowledge and skills (e.g., Earl, 2003; Wilson and Bai, 2010).

A compelling finding was that three case teachers' saw metacognitive prospects from assessment when it is connected to improvement purpose of teaching and learning. This was manifested in different ways relying on teachers different conceptions of assessment and metacognition. Nancy and Megan saw the opportunities of metacognitive development from a "formative" assessment task design of iteration, feedback and self-evaluation underpinning its development. A major part their perceptions of metacognition relates to cognitive regulation, which were found to connect with three aspects of assessment: supportive feedback, offering self-evaluative opportunities, developmental tasks of assessment design. These findings reiterate the close relationship between feedback and self-evaluation, and reflexive and critical thinking wellarticulated in a number of study (e.g., Andrade, 1999; Earl, 2003; Panadero et al., 2012). This resonates with an insight from the diffusion of assessment literature, that when involving selfevaluation and productive feedback, assessment could become a regulatory process in metacognition when students reflect upon and critical about the products and process of their work (cf. Andrade, 1999). By contrast, the notion of "paying attention," "focusing," and "metacognitive engaging" were central to Jason's thinking about metacognition, which was consistent with his interactive assessment practice of actively engaging students through probing. He valued classroom assessment and emphasized students' participation, which resonates with the second generation definition of AfL (Klenowski, 2009, p. 278), "assessment for learning is part of everyday practice by students, teachers and peers that seeks, reflects upon and responds to information from dialogue, demonstration and observation in ways that enhance ongoing learning."

Another interesting finding was that teachers' conception of assessment directing to student accountability would also involve teachers' conception of developing students' metacognition. While the teachers were equally committed to using assessment to improve teaching and learning, but varied to different degree in demonstrating student accountability. Megan saw multiple aspects of metacognition by considering students' dual roles as university students and future teachers. As for the role of university students, Megan referred metacognition as strategic awareness when dealing with assignments for good performance. For future teacher, she considered a higher level of self-awareness to become reflective teachers as an element of metacognition. These two elements were embedded in her beliefs of assessment, which highlighted the need to be relevant, engaging, authentic, and learning-oriented. Megan's understanding of the complex dual role played by students, and her intention to raise students' awareness thereof as a way to promoting metacognition, was reflected in her assessment design and practice. These conceptions reflect both accountability and learning purpose of assessment (Brown, 2004), and reiterate the value of both formative and summative as well as large-scale, standardsbased assessments, thus directing teachers toward a balanced perception toward different purpose of assessment (Looney, 2011). These would empower Megan with greater autonomy, and would open up more opportunities for metacognitive development in assessment literacy (Wyatt-Smith et al., 2010).

A major implication from the metacognitive development purpose of assessment highlights task design. All three teachers designed a series of tasks which involved students in the discipline through exploring how their language teaching is presented in a site, such as English Pedagogy; Learning and teaching the spoken and written language in the early primary years; Teaching literature and language arts in English. These vignettes about task design provide a flavor of two key elements in the analytical framework of assessment conception summarized by DeLuca et al. (2013): authentic learning tasks that are applicable and relevant to measurement; and an integrated understanding of assessment as a central process in teaching and learning. In a similar vein to the points made by Anderson and Hounsell (2007) the design of teaching, learning and assessment activities was crafted to draw students into performing authentic disciplinary dimension of thinking and learning. This confirms the findings from Andrade (1999) that authentic assessment encourages students to become autonomous and self-regulated adults, and assisted in making accurate and constructive selfassessments. Another finding connecting task design with cognitive regulation is intriguing as it directs our attention to how reflective thinking intertwining into task design to make students attending to and being aware of comprehension and task. It also implies that "developmental," "on-going," and "formative" are three characteristics of assessment task design that closely relate to regulation of cognition.

Another issue that warrants discussion is how to build metacognitive engagement in assessment. While both Nancy and Megan considered supportive feedback, offering selfevaluative opportunities, developmental tasks of assessment design as the three fundamental elements in assessment to metacognitively engage students, Jason valued "enjoyment," "confidence," "safe and non-threaten environment" to build metacognitive engagement in the classroom. This idea aligned with Willis (2010) who also believe belonging, trust, and respect are not regarded as peripheral to the learning within the classroom, but an essential social foundation that the teacher and students work together to continually maintain so that students would engage in the risky process (discussion of teaching literature in this case). This also in line with the idea proposed by Rogoff (1995) that when AfL practices are viewed as ways 
of enhancing participation, there is potential for learners to negotiate identities as autonomous learners.

The analysis also provides implications for assessment training. It is inferred that teachers' conceptions of assessment and metacognition could in many ways indicate whether or not teachers are assessment literate. Assessment literate teachers seem to be metacognition alert teachers. When teachers demonstrate a sound mastery of assessment principles and techniques to make sophisticated judgments about the validity of assessment practices in the targeted contexts, they would be more aware of students' metacognitive development when involved in assessment decision-making, and be more able to make metacognitive inference about students' learning.

While there was a shared alignment between teachers' knowledge and pedagogical understanding of metacognition and conceptions of assessment, the interview data also revealed some teacher dilemmas that may carry resonance for many teacher educators. In Nancy's case, although she stressed the reflective elements in assessment design to promote metacognitive knowledge, time constraints restricted her from enacting her beliefs; for example, she had too little time to unpack teaching by professionally critiquing experiences, although she thought it important for the development of students' metacognitive knowledge. In Megan's case, she confessed that, despite her awareness of the importance of promoting students' metacognition, in her actual teaching she would be preoccupied with classroom teaching itself-for instance, the need to cover certain content, syllabus items, and topics. Nevertheless, students' engagement with classroom teaching is one way she believes that could develop students' metacognitive awareness; this, to some extent, echoed Jason's conception, who emphasized metacognitively engaging through classroom participation.

\section{CONCLUSION}

This study explored the perceived integration of metacognition in teacher conceptions of assessment through the case study approach of three teacher educators in Hong Kong. The findings suggested that three case teachers' beliefs about learning purpose of assessment had a close connection with their perceptions of metacognition. In particular, authenticity and self-evaluation opportunities in assessment were both valued in Nancy's and Megan' perception of assessment which relates to cognitive regulation. Developmental and authentic task design was perceived by Nicole to have relationship with reflective and critical thinking, which bring the connection between assessment task design and regulation of cognition. In the case of Megan, she identified dual role of students' metacognition: students' strategic knowledge to achieve better academic performance; and their self-awareness of being a reflective teacher to improve learning, thus giving equal weight to both accountability and learning purpose of assessment. In Jason's case, he related metacognition to students' metacognitive engagement. This was consistent with his beliefs of classroom-based interactive assessment, involving classroom interactive questioning to assess and engage students, as a potential way to develop students into autonomous learners.
Despite its exploratory nature, this study represents one of the few attempts to depict the interactions between teacher educators' conceptions of assessment and conceptions of metacognition. It has a number of implications for professional development and practice regarding embedding element of metacognition in assessment. This research showed that teachers' conceptions of metacognition closely bond with conceptions of assessment when teachers opt for positive attitude to the improvement purpose of assessment. Practically, this suggests that in professional development in assessment literacy efforts should be intended to teachers' commitment to improving their own instruction and the learning of their own students rather than on the mastery of assessment principles. Promoting teachers' knowledge of and pedagogical understanding of metacognition is helpful for teachers in raising positive attitude toward improvement purpose of assessment. Moreover, Megan case has shown a good example of combining both accountability and learning purpose of assessment by interacting with students' dual roles as university students and future teachers in the university classroom. This finding implies the importance of promoting teacher's pedagogical understanding of metacognition in relation to assessment, for example, knowledge about assessment practices that could trigger students' strategic awareness when dealing with assignment, may minimize the negative attitude association with accountability purposes. Another practical implication directs teachers and teacher educators' attention to students' metacognitive participation and encourage teachers to gain more knowledge and understanding on how student learn in classroom assessment. The interplay of pedagogical understanding of metacognition, students' metacognitive participation, and teachers' actual assessment practice is worth further exploration.

\section{DATA AVAILABILITY STATEMENT}

All datasets generated for this study are included in the article/Supplementary Material.

\section{ETHICS STATEMENT}

This study was carried out in accordance with the recommendations of Research Ethics in Social Science, Ethics Committee of the University of Hong Kong. The protocol was approved by Ethics Committee of the University of Hong Kong. All subjects gave written informed consent in accordance with the Declaration of Helsinki.

\section{AUTHOR CONTRIBUTIONS}

The author confirms being the sole contributor of this work and has approved it for publication.

\section{SUPPLEMENTARY MATERIAL}

The Supplementary Material for this article can be found online at: https://www.frontiersin.org/articles/10.3389/feduc. 2019.00157/full\#supplementary-material 


\section{REFERENCES}

Aguirre, J., and Speer, N. M. (1999). Examining the relationship between beliefs and goals in teacher practice. J. Math. Behav. 18, 327-356. doi: 10.1016/S0732-3123(99)00034-6

Anderson, C., and Hounsell, D. (2007). Knowledge practices: 'Doing the subject' in undergraduate courses. Curric. J. 18, 463-478. doi: 10.1080/09585170701687910

Andrade, H. G. (1999). "Student self-assessment: at the intersection of metacognition and authentic assessment," A paper presented at the annual meeting of the American Educational Research Association, Montreal, QC. Retrieve from: https://files.eric.ed.gov/fulltext/ED431030.pdf (accessed April 20, 1999).

Bartz, D., Anderson-Robinson, S., and Hillman, L. (1994). Performance assessment: make them show what they know. Principal 73, 11-14.

Black, P., and Wiliam, D. (1998). Assessment and classroom learning. Assess. Educ. 5, 7-74. doi: 10.1080/0969595980050102

Borko, H., Mayfield, V., Marion, S., Flexer, R., and Cumbo, K. (1997). Teachers' developing ideas and practices about mathematics performance assessment: successes, stumbling blocks, and implications for professional development. Teach. Teach. Educ. 13, 259-278. doi: 10.1016/S0742-051X(96)00024-8

Brookhart, S. M. (2002). "What will teachers know about assessment, and how will that improve instruction," in Assessment in Educational Reform: Both Means and Ends, eds R. W. Lizzitz and W. D. Schafer (Boston, MA: Allyn and Bacon), 2-17.

Brookhart, S. M. (2011). Educational assessment knowledge and skills for teachers. Educ. Meas. 30, 3-12. doi: 10.1111/j.1745-3992.2010. 00195.x

Brown, A. L. (1987). "Metacognition, executive control, self-regulation, and other more mysterious mechanisms," in Metacognition, Motivation, and Understanding, Vol. 65, eds F. E. Weinert and R. H. Kluwe (Hillsdale, MI: Laurence Erlbaum Associates), 116.

Brown, G. T. L. (2004). Teachers' conceptions of assessment: implications for policy and professional development. Assess. Educ. 11, 305-322. doi: 10.1080/0969594042000304609

Brown, G. T. L. (2006). Teachers' conceptions of assessment: validation of an abridged instrument. Psychol. Rep. 99, 166-170. doi: 10.2466/PR0.99.5.166-170

Brown, G. T. L. (2008). "Assessment literacy training and teachers' conceptions of assessment," in Challenging Thinking About Teaching and Learning, eds C. Rubie-Davies and C. Rawlinson (New York, NY: Nova Science), 285-302.

Butler, D. L., and Winne, P. H. (1995). Feedback and self-regulated learning: a theoretical synthesis. Rev. Educ. Res. 65, 245-281. doi: $10.3102 / 00346543065003245$

Calderhead, J. (1996). “Teachers' beliefs and knowledge," in Handbook of educational psychology, eds D. C. Berliner and R. C. Calfee (New York, NY: Simon \& Schuster Macmillan), 709-725.

Carless, D. (2010). From Testing to Productive Student Learning: Implementing Formative Assessment in Confucian-Heritage Settings. New York, NY: Routledge.

Carless, D. (2015). Excellence in University Assessment: Learning From AwardWinning Practice. London: Routledge. doi: 10.4324/9781315740621

Cheung, D., and Wong, H. W. (2002). Measuring teacher beliefs about alternative curriculum designs. Curric. J. 13, 225-248. doi: 10.1080/095851702101 36868

Clark, C., and Peterson, P. (1986). "Teachers' thought processes," in Handbook of Research on Teaching, 3rd Edn, ed. M. Wittrock (New York, NY: MacMillan), 255-296.

Clark, K. F., and Graves, M. F. (2005). Scaffolding students' comprehension of text. Read. Teach. 58, 570-580. doi: 10.1598/RT.58.6.6

Cowie, B., Cooper, B., and Ussher, B. (2014). Developing an identity as a teacherassessor: three student teacher case studies. Assess. Matters 7, 64-89.

Crossman, J. (2007). The role of relationships and emotions in student perceptions of learning and assessment. High. Educ. Res. Dev. 26, 313-327. doi: 10.1080/07294360701494328

De Backer, L., Van Keer, H., and Valcke, M. (2012). Exploring the potential impact of reciprocal peer tutoring on higher education students' metacognitive knowledge and regulation. Instruct. Sci. 40, 559-588. doi: 10.1007/s11251-011-9190-5
Delandshere, G., and Jones, J. H. (1999). Elementary teachers' beliefs about assessment in mathematics: a case of assessment paralysis. J. Curric. Supervis. 14:216.

DeLuca, C., and Bellara, A. (2013). The current state of assessment education: aligning policy, standards, and teacher education curriculum. J. Teach. Educ. 64, 356-372. doi: $10.1177 / 0022487113488144$

DeLuca, C., Chavez, T., and Cao, C. (2013). Establishing a foundation for valid teacher judgement on student learning: the role of pre-service assessment education. Assess. Educ. 20, 107-126. doi: 10.1080/0969594X.2012.668870

Earl, L. (2003). Assessment as Learning: Using Classroom Assessment to Maximize Student Learning. Thousand Oaks, CA: Corwin.

Ekeblad, E., and Bond, C. (1994). "The nature of a conception: questions of context," in Phenomenography: Philosophy and Practice, eds R. Ballantyne and C. Bruce (Brisbane, QLD: Queensland University of Technology, Centre for Applied Environmental and Social Education Research), 343-353.

Estacion, A., McMahon, T., Quint, J., Melamud, B., and Stephens, L. (2004). Conducting Classroom Observations in First Things First Schools: Working Paper. Kansas City, MO: IRRE.

Flavell, J. H. (1979). Metacognition and cognitive monitoring. Am. Psychol. 34, 906-911. doi: 10.1037/0003-066X.34.10.906

Gourgey, A. F. (1999). Teaching reading from a metacognitive perspective: theory and classroom practice. J. Coll. Read. Learn. 30, 85-94. doi: $10.1080 / 10790195.1999 .10850087$

Graham, P. (2005). Classroom-based assessment: changing knowledge and practice through preservice teacher education. Teach. Teach. Educ. 21, 607-621. doi: 10.1016/j.tate.2005.05.001

Guba, E. G., and Lincoln, Y. S. (1981). Effective Evaluation: Improving the Usefulness of Evaluation Results Through Responsive and Naturalistic Approaches. San Francisco, CA: Jossey-Bass.

Haney, W. (1991). "We must take care: fitting assessments to functions," in Expanding Student Assessment, ed. V. Perrone (Alexandria, VA: Association for Supervision and Curriculum Development), 142-163.

Harootunian, B., and Yarger, G. P. (1981). Teachers' Conceptions of Their Own Success: Current Issues. Washington, DC: ERIC Clearinghouse on Teacher Education.

Hawkins, J., Frederiksen, J., Collins, A., Bennett, D., and Collins, E. (1993). Assessment and technology. Commun. ACM, 36, 74-77. doi: $10.1145 / 155049.155068$

Howley, M. D., Howley, A., Henning, J. E., Gillam, M. B., and Weade, G. (2013). Intersecting domains of assessment knowledge: school typologies based on interviews with secondary teachers. Educ. Assess. 18, 26-48. doi: 10.1080/10627197.2013.761527

Ibabe, I., and Jauregizar, J. (2010). Online self-assessment with feedback and metacognitive knowledge. High. Educ. 59, 243-258. doi: 10.1007/s10734-009-9245-6

Klenowski, V. (2009). Assessment for learning revisited: an Asia-Pacific perspective. Assess. Educ. 16, 263-268. doi: 10.1080/09695940903319646

Kvale, S. (2001). The psychoanalysis interview as qualitative research. Psychol. Test Assess. Model. 43, 9-31.

Levy-Vered, A., and Alhija, F. N.-A. (2015). Modelling beginning teachers' assessment literacy: the contribution of training, selfefficacy, and conceptions of assessment. Educ. Res. Eval. 21, 378-406. doi: 10.1080/13803611.2015.1117980

Looney, J. W. (2011). "Integrating formative and summative assessment: progress toward a seamless system?" OECD Education Working Papers, No. 58, Paris: OECD Publishing. doi: 10.1787/5kghx3kbl734-en

Lortie, D. (1975). Schoolteacher: A Sociological Study. London: University of Chicago Press.

Marton, F. (1981). Phenomenography-describing conceptions of the world around us. Instruc. Sci. 10, 177-200. doi: 10.1007/BF00132516

Merriam, S. B. (2001). Qualitative Research and Case Study Applications in Education. Revised and Expanded from Case Study Research in Education. San Francisco, CA: Jossey-Bass Publishers.

Miles, M. B., and Huberman, A. M. (1994). Qualitative Data Analysis: An Expanded Sourcebook. Thousand Oaks, CA: Sage.

Ottenhoff, J. (2011). Learning how to learn: metacognition in liberal education. Liberal Educ. 97, 28-33. Retrieved from: http://eproxy.lib.hku.hk/login? 
url=http://search.ebscohost.com/login.aspx?direct=true\&db=eric\&AN= EJ962013\&site=ehost-live

Pajares, M. F. (1992). Teachers' beliefs and educational research: cleaning up a messy construct. Rev. Educ. Res. 62, 307-332. doi: 10.3102/00346543062003307

Panadero, E., Alonso-Tapia, J., and Huertas, J. A. (2012). Rubrics and self-assessment scripts effects on self-regulation, learning and selfefficacy in secondary education. Learn. Indiv. Diff. 22, 806-813. doi: 10.1016/j.lindif.2012.04.007

Panadero, E., Alonso-Tapia, J., and Reche, E. (2013). Rubrics vs. self-assessment scripts effect on self-regulation, performance and self-efficacy in pre-service teachers. Stud. Educ. Eval. 39, 125-132. doi: 10.1016/j.stueduc.2013.04.001

Panadero, E., and Jonsson, A. (2013). The use of scoring rubrics for formative assessment purposes revisited: a review. Educ. Res. Rev. 9, 129-144. doi: 10.1016/j.edurev.2013.01.002

Pratt, D. D. (1992). Conceptions of teaching. Adidt Educ. Q. 42, 203-220. doi: $10.1177 / 074171369204200401$

Pryor, J., and Crossouard, B. (2008). A socio-cultural theorisation of formative assessment. Oxf. Rev. Educ. 34, 1-20. doi: 10.1080/030549807014 76386

Quilter, S. M., and Chester, C. (1998). "Inservice teachers' perceptions of educational assessment," Paper presented at the Annual Meeting of the MidWestern Educational Research Association, Chicago, IL.

Remesal, A. (2011). Primary and secondary teachers' conceptions of assessment: a qualitative study. Teach. Teach. Educ. 27, 472-482. doi: 10.1016/j.tate.2010.09.017

Rex, L. A., and Nelson, M. C. (2004). How teachers' professional identities position high-stakes test preparation in their classrooms. Teach. Coll. Rec. 106, 1288-1331. doi: 10.1111/j.1467-9620.2004.00380.x

Rogoff, B. (1995). "Observing sociocultural activity on three planes: participatory appropriation, guided participation, and apprenticeship," in Sociocultural Studies of Mind, eds J. Wertsch, P. Del Rio, and A. Alvarez (Cambridge: Cambridge University Press), 139-164. doi: 10.1017/CBO9781139174299.008

Scarino, A. (2013). Language assessment literacy as self-awareness: understanding the role of interpretation in assessment and in teacher learning. Lang. Test. 30, 309-327. doi: $10.1177 / 0265532213480128$

Sternberg, R. J. (1998). Metacognition, abilities, and developing expertise: what makes an expert student? Instruc. Sci. 26, 127-140.

Stiggins, R. J. (1995). Assessment literacy for the 21st century. Phi Delta Kappan $77,238-245$
Thompson, A. G. (1992). "Teachers' beliefs and conceptions: a synthesis of the research," in Handbook of Research on Mathematics Leaching and Learning, ed. D. A. Grouws (New York, NY: Macmillan), 127-146.

Van den Berg, R. (2002). Teachers' meanings regarding educational practice. Rev. Educ. Res. 72, 577-625. doi: 10.3102/00346543072004577

Wen, Y.-H. (2012). A study on metacognition of college teachers. J. Hum. Res. Adult Learn. 8, 80-91. Retrived from: http://www.hraljournal.com/Page/ $9 \% 20$ Wen, \%20Ya-Hui.pdf

Willis, J. (2010). Assessment for learning as a participative pedagogy. Assess. Matters 2, 65-84. Retrived from http://eprints.qut.edu.au/37641/1/c37641.pdf

Wilson, N. S., and Bai, H. (2010). The relationships and impact of teachers'metacognitive knowledge and pedagogical understandings of metacognition. Metacogn. Learn. 5, 269-288. doi: 10.1007/s11409-010-9062-4

Wise, S. L., Lukin, L. E., and Roos, L. L. (1991). Teacher beliefs about training intesting and measurement. J. Teach. Educ. 42, 37-42. doi: $10.1177 / 002248719104200106$

Wyatt-Smith, C., Klenowski, V., and Gunn, S. (2010). The centrality of teachers judgement practice in assessment: a study of standards in moderation. Assess. Educ. 17, 59-75. doi: 10.1080/09695940903565610

$\mathrm{Xu}, \mathrm{Y}$., and Brown, G. T. (2016). Teacher assessment literacy in practice: a reconceptualization. Teach. Teach. Educ. 58, 149-162. doi: 10.1016/j.tate.2016.05.010

Zohar, A. (1999). Teachers' metacognitive knowledge and the instruction of higher order thinking. Teach. Teach. Educ. 15, 413-429. doi: 10.1016/S0742-051X(98)00063-8

Zohar, A., and Barzilai, S. (2013). A review of research on metacognition in science education: current and future directions. Stud. Sci. Educ. 49, 121-169. doi: 10.1080/03057267.2013.847261

Conflict of Interest: The author declares that the research was conducted in the absence of any commercial or financial relationships that could be construed as a potential conflict of interest.

Copyright $\odot 2020$ Wang. This is an open-access article distributed under the terms of the Creative Commons Attribution License (CC BY). The use, distribution or reproduction in other forums is permitted, provided the original author(s) and the copyright owner(s) are credited and that the original publication in this journal is cited, in accordance with accepted academic practice. No use, distribution or reproduction is permitted which does not comply with these terms. 